\title{
Efficiency and Reliability Assessments of Retrofitted High-Efficiency Motors
}

\author{
John S. Hsu (Htsui), Pedro J. Otaduy, John D. Kueck \\ Oak Ridge National Laboratory \\ Post Office Box 2003, K-1220, MS 7280 \\ Oak Ridge, Tennessee 37831-7280
}

\section{Abstract:}

The majority of electric-motor applications are pumps, fans, blowers, and certain compressors that follow the load torque pattern described in this paper. It has been known for many years that simply replacing the old motor with a highefficiency motor might not produce the expected efficiency gain.

This paper suggests the calculations for the effective efficiency and temperature rise of the high-efficiency motor. The reliability in terms of temperature rise, downsizing, power factor, harmonics, mechanical structure, etc., are discussed.

\section{INTRODUCTION}

Over one billion motors currently convert electricity into useful work in the United States. Nearly $70 \%$ of all electricity used in industry is devoted to motor-driven equipment [1]. The potential benefits of improved efficiency include not only the energy and cost savings, but also the significant reductions of greenhouse gas emissions.

In order to maximize energy savings, the entire chain of the electric motor drive system, starting from power system terminals at the plant via the motor drives, including the driven mechanical device, and finally reaching the manufacturing processes, must be considered [1]. As an example, Fig. 1 shows the chain of a pump or fan drive system.

The motor is an important component in the chain of a drive system. There are basically two types of highefficiency electric motors available in the market. One is the optimized NEMA design-B type, the other one is a new design-A type with minimum efficiency specified, and is

A paper presented and distributed in the DOE's Tool and Protocol Workshop of Motor Challenge Program, Sept. 2223. Chicago, Illinois for discussion. Manuscript of this paper submitted to IEEE September, 1994.

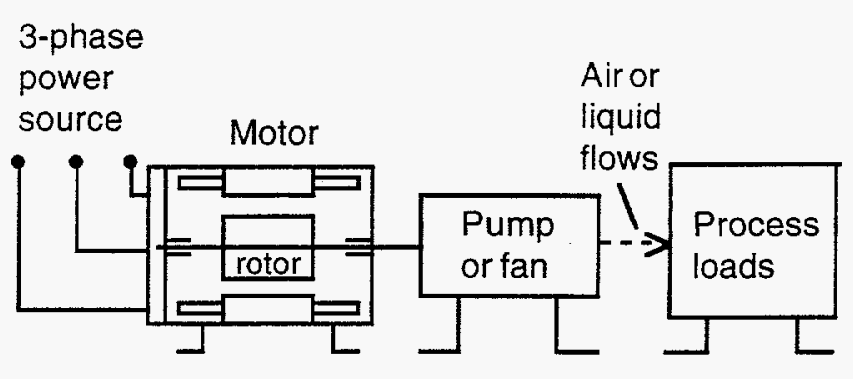

Fig.1 A motor drive system

redesignated as design-E type [2]. Design B motors have lower inrush current and torque values than those of design$\mathrm{E}$ motors. For a given rating, the inrush current for design A is usually $15 \%$ to $20 \%$ higher than that of design B. The starters for design A have to meet the inrush-current demand.

Fig. 2 shows the slip and losses for a group of 2-pole

\section{Slip \& Losses}

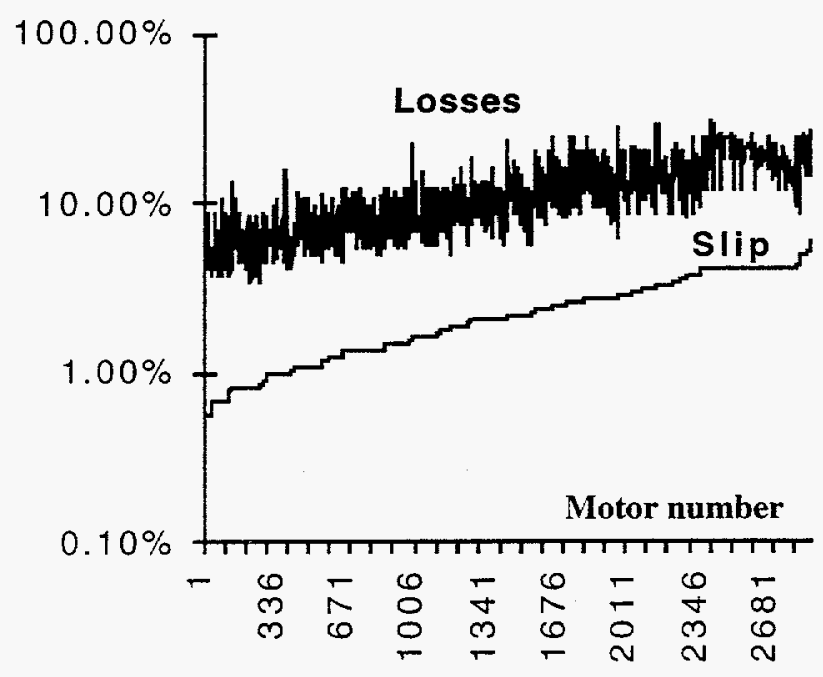

Fig. 2 Slip and losses for a population of 2800 two-pole motors (Note, Motor set ordered by magnitude of slip and hp output)

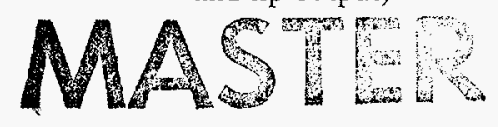


motors that are set up in sequence according to their slips and horsepower outputs. Approximately 2800 two-pole motors stored in the data base of Motor Master [3] were screened. The speeds for high-efficiency motors having lower losses are generally higher than those of the ordinary motors. For equal speed, the higher horsepower motors have lower losses.

Motor efficiency is the ratio of shaft output power to motor input power. From a user's standpoint, this motoralone efficiency is not as important as the efficiency that the user actually sees. A drive system retrofitted with a highefficiency motor may be expected to produce a significant energy saving according to the motor's nameplate. Nevertheless, for certain types of loads, adverse effects might take place that not only reduce the actual overall energy gain but also may result in a higher temperature rise in the motor.

Bonnett [2] points out that $65 \%$ of the electric motor applications are pumps, fans, blowers and compressors. A major portion of these devices follows a similar pattern of torque and power characteristics. The required driving torque is proportional to speed square, and the required driving power is proportional to speed cube.

Nailen [4] clearly explains through an example that the energy saving is not as high as that shown in the highefficiency-motor nameplate. When a standard design motor running at $1760 \mathrm{r} / \mathrm{min}$ is substituted by a high-efficiency motor running at $1780 \mathrm{r} / \mathrm{min}$, the pump demands $5 \%$ more power.

This paper presents the calculations and assessments for the effective efficiency that takes the drive system into consideration and for the temperature rise and the reliability of the retrofitted high-efficiency motor. The reliability is studied in terms of temperature rise, motor down-sizing, harmonics, and mechanical aspects. Relevant literature is listed in the reference section (1-12).

\section{EFFECTIVE EFFICIENCY AND TEMPERATURE RISE}

Fig. 3a shows the motor torques of a typical old motor and of the retrofitted high-efficiency new motor. The new motor has less rotor copper loss and runs at higher speed than the old motor. The load is a pump, but can be a fan or other devices, whose required driving torque is proportional to the speed square, and the required power is proportional to the speed cube. The corresponding pump torque and pump power curves are shown.

The enlarged portion of Fig. 3a is given in Fig. 3b. The old motor torque intersects the pump torque demand curve at point $\mathrm{A}$, and the new high-efficiency motor torque intersects the same pump curve at point $B$. The corresponding motor speeds and pump powers can be obtained by projecting points $\mathrm{A}$ and $\mathrm{B}$ downward. Point $\mathrm{C}$ on the pump power curve indicates the old output power of the old motor, and point $\mathrm{D}$ represents the new output power

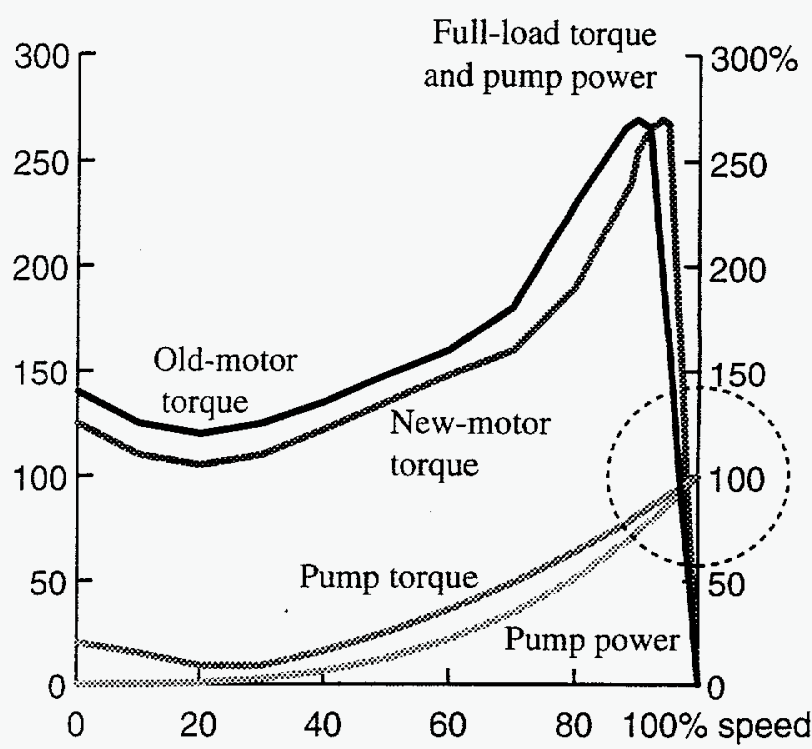

(a) Motor torque, pump torque, and pump power curves

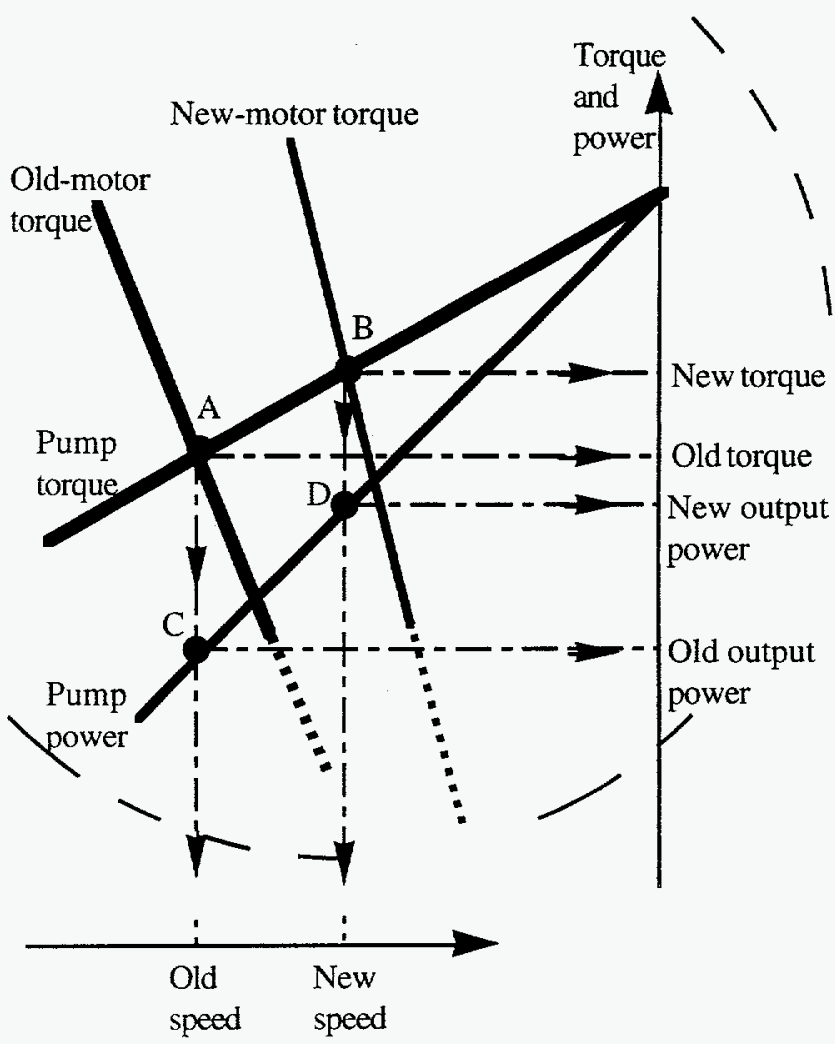

(b) Intersecting points, A and B, of motor and pump torques

Fig. 3 Old and new speeds, output torques, and powers without changing pump system 
of the high-efficiency motor. The speeds for the old and the new motors are also shown in Fig. 3b. The highefficiency new motor runs at higher speed than the old one. Subsequently, the torque and the output power of the highefficiency new motor are also higher than the old motor's.

\section{A. Effective Efficiency}

Effective efficiency without changing the pump system is the new motor output less the wasted power in the pump, then divided by the power input of the new motor. Its derivation is given in Appendix 1. The result is presented by equation (1).

$\eta_{\text {eff. }}=\eta_{\text {new }} \cdot\left(\frac{1-S_{\text {old }}}{1-S_{\text {new }}}\right)^{3}$

where $\eta_{\text {eff }}$ is the effective efficiency of the new motor,

$\eta_{\text {new }}$ is the new efficiency of the new motor alone,

$S_{\text {old }}$ is the old slip of the old motor

and $S_{\text {new }}$ is the new slip of the new motor

Example: A 4-pole, $60-\mathrm{Hz}$ induction fan motor is replaced by a high-efficiency new motor. The efficiency and speed of the old motor are 0.890 and $1760 \mathrm{r} / \mathrm{min}$, respectively. For the new motor they are 0.920 and 1780 $\mathrm{r} / \mathrm{min}$, respectively.

Substituting the above data into equation (1) gives the effective efficiency when the fan system remains unchanged.

$$
\begin{aligned}
\eta_{\text {eff. }} & =\eta_{\text {new }} \cdot\left(\frac{1-S_{\text {old }}}{1-S_{\text {new }}}\right)^{3}=0.920 \cdot\left(\frac{1-0.0222}{1-0.0111}\right)^{3} \\
& =0.889
\end{aligned}
$$

where

$$
\begin{aligned}
& S_{\text {old }}=\frac{1800-1760}{1800}=0.0222 \\
& \text { and } S_{\text {new }}=\frac{1800-1780}{1800}=0.0111 .
\end{aligned}
$$

The effective efficiency of 0.889 does not show any energy gain from the replacement of the old motor by a high-efficiency motor if the fan system remains unchanged.

\section{B. Temperature Rise Assessment}

Table 1 shows the NEMA [5] permissible temperature rises of non-totally enclosed and non-encapsulated motors with a 1.15 service-factor. The estimated temperature rises based on experience at full load for insulation classes B and $\mathrm{F}$ are around $70^{\circ} \mathrm{c}$ and $90^{\circ} \mathrm{c}$, respectively.

Derivation from the relationships between temperature

\begin{tabular}{|l|c|c|}
\hline Class of insulation system & $\mathrm{B}$ & $\mathrm{F}$ \\
\hline Estimated temperature rise at full load & $(70 \mathrm{c})$ & $(90 \mathrm{c})$ \\
\hline $\begin{array}{l}\text { NEMA temperature rise at } 1.15 \text { service } \\
\text { factor }\end{array}$ & $90 \mathrm{c}$ & $115 \mathrm{c}$ \\
\hline
\end{tabular}

Maximum ambient temperature $=40$ degrees $\mathrm{c}$

Table 1 Permissible temperature rises of non-totallyenclosed and nonencapsulated motors at $1.15 \mathrm{SF}$

rise and load given in Table 1 indicates that the temperature rise is exponentially proportional to the 1.8 th power of the ratio of actual output to the output of the known temperature rise.

$$
\Delta T_{\text {new }}=\Delta T_{\text {known }} \cdot\left(\frac{P_{\text {output new }}}{P_{\text {output known }}}\right)^{1.8}
$$

where $\Delta \mathrm{T}_{\text {new }}$ is the new temperature rise under the new power output, and $\Delta T_{\text {known }}$ is the known temperature rise under the known power output, $\mathrm{P}_{\text {output known }}$.

The output-power ratio of the new motor to the old motor is proportional to the cube of the ratio of their speeds. Substituting this relationship into (2) gives the temperature rise of the retrofitted new motor.

$$
\Delta T_{\text {new }}=\Delta T_{\text {new motor known }} \cdot\left(\frac{1-S_{\text {new motor }}}{1-S_{\text {old motor }}}\right)^{5.4}
$$

If the old motor given in the previous example runs at full load with a nameplate temperature rise of $80^{\circ} \mathrm{c}$, and the high-efficiency new motor has the same horse-power rating and the same nameplate temperature rise, the temperature of the new retrofitted high-efficiency motor can be obtained through equation (3).

$$
\begin{aligned}
\Delta T_{\text {new }} & =\Delta T_{\text {new motor known }}\left(\frac{1-S_{\text {new motor }}}{1-S_{\text {old motor }}}\right)^{5.4} \\
& =80^{\circ} \mathrm{c} \cdot\left(\frac{1-0.0111}{1-0.0222}\right)^{5.4}=85^{\circ} \mathrm{c} .
\end{aligned}
$$

This higher temperature rise may shorten the life expectancy of the retrofitted new motor when the fan system remains unchanged.

\section{RELIABILITY ASSESSMENTS}

Safety and reliability in operating a plant are paramount priorities. Unexpected down time is often not only very expensive but it wastes energy, equipment utilization time, and affects workers' morale. 


\section{A. Motor Temperature-Rise Consideration}

For the optimized design-B type of high-efficiency motors, the internal motor cooling fans are optimized to reduce friction and windage loss within the permissible temperature rise of the insulation system of the motor. There is no abundant room for higher temperature ratings. Especially when the motor is designed with a service factor of 1.0, the temperature rise must be assessed before replacing the old motor with a high-efficiency motor.

\section{B Downsizing Consideration}

Unusual electric-motor service conditions, such as the voltage dips and unbalanced voltages, do happen. It is necessary to have a certain margin in motor output power rating for reliability considerations.

When the power required for a specific motor

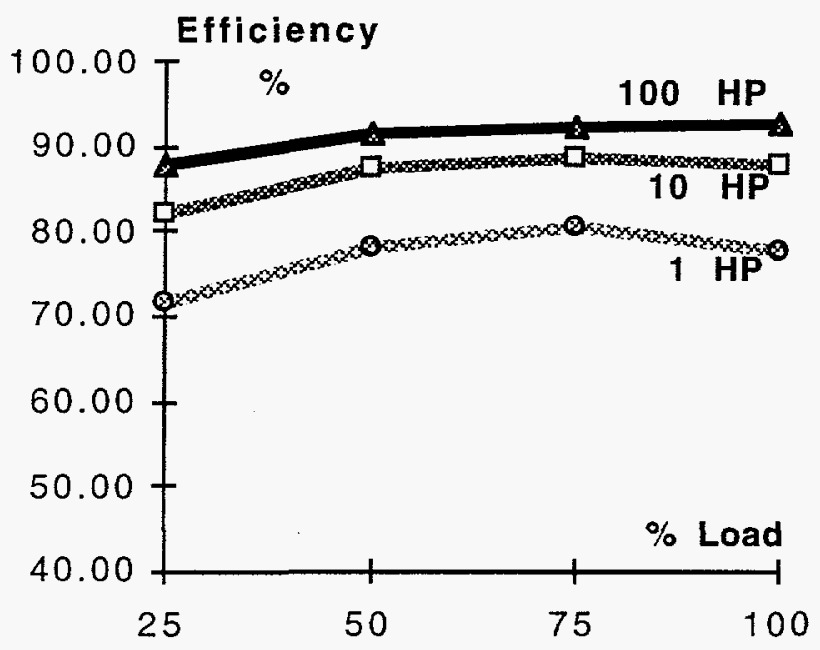

Fig. 4 Average efficiency versus load for 2-pole motors

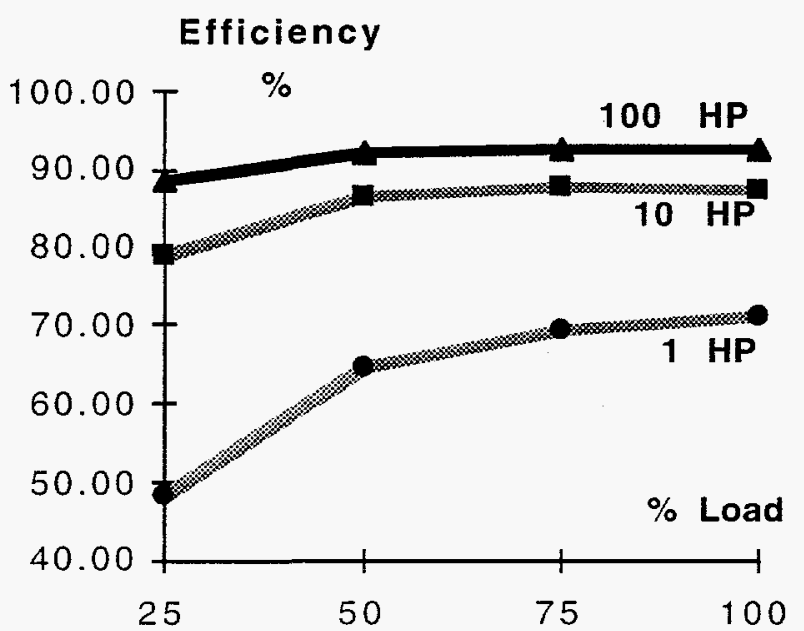

Fig. 5 Average efficiency versus load for 8-pole motors

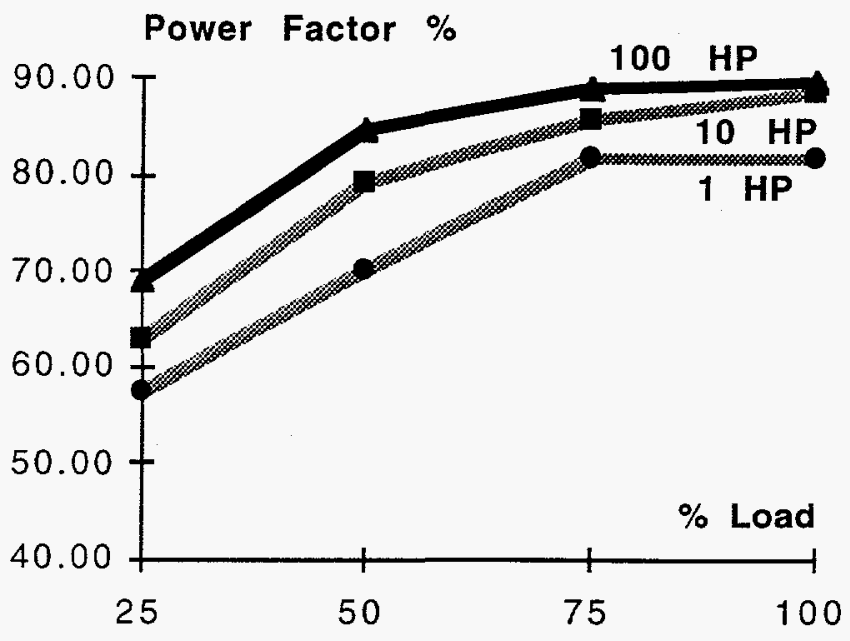

Fig. 6 Power factor versus load for 2-pole motors

Power Factor \%

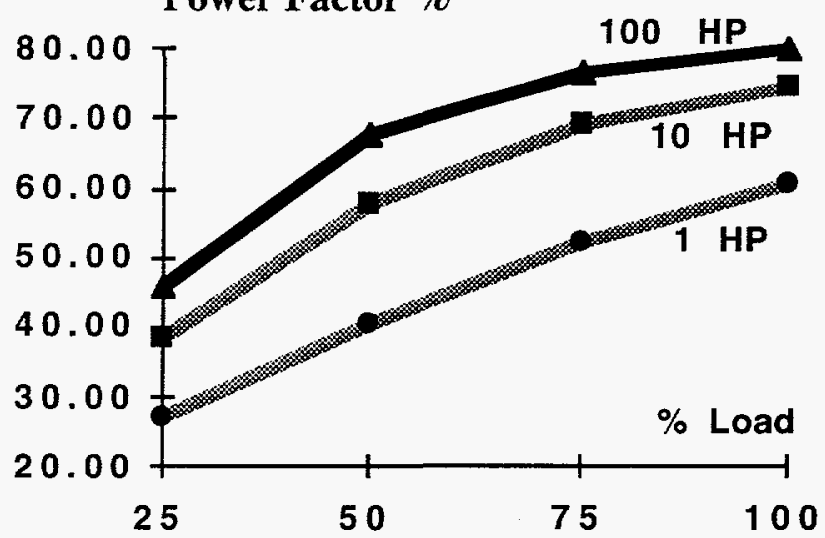

Fig. 7 Power factor versus load for 8-pole motors

application is to be determined by testing, proper belt-andpulley slip allowance, and valve, damper, and other settings that may lower the maximum load must be checked and corrected prior to the maximum load test.

Typical efficiency and power factor versus load curves for 4-pole $(1800-r / m i n)$, three-phase, design-B induction motors are given in NEMA's publication [6]. In order to see the efficiency variations affected by the number of poles and horsepower ratings, the overall efficiency versus load characteristics for the high-speed (2-pole) and lowspeed (8-pole) motors of different horsepower ratings are further examined through statistical plottings. Fig. 4 shows the average efficiencies of two-pole motors versus percentage of load for 1,10 , and $100 \mathrm{hp}$, respectively. There are approximately a thousand 2-pole motors for fullload data of each rating. The available efficiency data stored in the data file of Motor Master goes down as the percentage of load decreases. Fig. 5 shows similar curves for 8-pole motors plotted from relatively less motor data available in the same data file. 
For both high- and low-speed motors, Figs. 4 and 5 clearly indicate that the efficiency variations between $100 \%$ and $50 \%$ loads for higher horsepower ratings, such as 100 $\mathrm{hp}$, are small. For lower horsepowers, such as $1 \mathrm{hp}$, the highest efficiency occurs in the region between $100 \%$ and $50 \%$ loads.

For motors with both low speed and low horsepower, a change of efficiency-versus-load pattern is observed. For example, the 8-pole, 1-hp efficiency curve in Fig. 5 has a continuous declining tendency as the percentage of load decreases. Therefore, arbitrarily downsizing existing motors without analysis in order to save energy is inappropriate.

\section{Power Factor Consideration}

Figs. 6 and 7 show that unlike the efficiency-versus-load curves, the power factor drops as the percentage of load goes down. The rate of descending is generally greater for lower horsepowers and for slower speeds as shown by the curves of 1-hp and 8-pole motors in the figures. When a plant has a significant number of motors that are not fully loaded, the power factor of the plant load becomes poor.

Power factor corrections can save energy that otherwise is consumed in the supply system. However, caution must be given for not overly compensating the motor power factor. Otherwise, self-excitation may occur that can destroy the motor insulation system. It is advisable to check with motor manufacturers for the maximum permissible capacitances for power factor corrections.

\section{System Harmonics Consideration}

Nonlinear loading, such as power-electronic devices, increasingly affects power supplies, therefore harmonic effects on motor losses and torque outputs have to be considered. Assuming the motor has three symmetrical phases, its voltages and currents can be grouped into zero-, positive-, and negative-sequence components. Correspondingly, they produce no torque, forward torque, and backward torque.

Subharmonic (lower than line frequency) currents may possibly appear in the motor supplies and cause additional losses. Multiple cycles of currents are used to detect subharmonics.

For normal symmetrical phase harmonics, the forward torque producers are harmonics multiple of three plus one (i. e., $1,4,7,10,13 \ldots$ etc.) whose phase sequencing coincides with the direction of rotation and contributes to the operation of the motor. The backward torque producers are harmonics multiple of three plus two (i. e., 2, 5, 8, .. etc.) whose phase sequencing is opposite to the direction of rotation. All of the energy of the backward harmonics goes to heat. In addition, they slow down the rotor forcing higher currents of forward harmonic to compensate for the lost torque and thus backward harmonics increase the overall losses further.

For a particular torque producing harmonic frequency, the equivalent circuit for an induction motor is similar to the locked rotor equivalent circuit. The magnetizing branch of the equivalent circuit may be neglected in a harmonic equivalent circuit because the magnetizing reactance is much larger than the rotor leakage impedance. Also, since the slip for a typical harmonic frequency is much larger than that for the fundamental, the presence of harmonic voltages can give rise to substantially higher harmonic currents.

Ref. [7] uses harmonic equivalent circuit parameters to develop expressions for the harmonic current losses. This reference suggests that the $5 \%$ total voltage harmonic distortion (THD) limit of IEEE Guide 519 [8] may not be sufficiently limiting to protect induction motors from thermal damage. This reference also finds that the second harmonic has the most pronounced effect on temperature rise and calculates a derating factor of approximately $6 \%$ for a 5-hp motor operating with a 5\% second harmonic of voltage and $20 \%$ for a 5 -hp motor operating with an $8 \%$ second harmonic of voltage.

On the other hand, IEEE 519 [8] indicates that a total harmonic distortion factor of up to $5 \%$ can normally be tolerated on industrial power systems, where the distortion factor is the square root of the sum of the squares of the individual harmonic amplitudes divided by the square of the amplitude of the fundamental.

Similarly, NEMA Standard MG1 (5) also provides a discussion on derating motors for harmonic content. The intent of the NEMA guidance is to derate the motor to prevent overheating that could damage the motor. In the NEMA Standard, a 5\% harmonic voltage factor results in a motor derating of approximately $3.5 \%$. The NEMA derating method neglects accounting for even and triplen (multiples of three) harmonics. However, in many industrial applications, triplen harmonics do exist, and even harmonics are sometimes present because nonlinearities can distort the waveform nonsymmetrically about the wave average.

\section{E. Motor Mechanical Feature Consideration}

In general, design-B-type high-efficiency motors are designed with more magnetic material. a longer rotor, and, sometimes. a smaller air gap. A voltage imbalance of $2 \%$ may result in a power imbalanceof $10 \%$. Power imbalances result in a $120-\mathrm{Hz}$ ripple on the three-phase power waveform and in $120-\mathrm{Hz}$ magnetic field oscillations. 
When there is eccentricity in a two-pole motor due to worn bearings or assembly tolerance, a $120-\mathrm{Hz}$ mechanical vibration is generated as the rotor is pushed back and forth radially by the imbalanced field. An air gap on a 300-hp NEMA Design-B high-efficiency motor may be only $2 \mathrm{~mm}$. As bearings wear, the eccentricity of the air gap is increased, allowing greater flux linkage and higher magnetic radial force imbalances. These imbalances may result in faster wear in high-efficiency motors because of the longer rotor and smaller air gap. As some users of highefficiency motors have observed, once significant vibration is detected, motor failure must be considered as being relatively near term.

Insulated bearings can be used to prevent bearing damages caused by shaft currents in large motors.

As discussed earlier, many high-efficiency motors are being specified with service factors of one which indicates that their design thermal margin is small. Thus any service condition that results in an increase of heat in the motor can be detrimental, especially if the increased heating leads to imbalances, either mechanical or electrical. The authors have had experience with inductive imbalance in the stators of high-efficiency motors. Preliminary data analysis on particular motors indicates that the inductive imbalance grows as the $120-\mathrm{Hz}$ vibration grows.

High-efficiency motors may be more sensitive to terminal voltage and internal inductive imbalances. Voltage imbalance in a motor feeder can take two forms, either imbalance of the voltage amplitudes or imbalance of the displacement angles between the phase voltages. A voltage imbalance not only creates an imbalance in the power supplied to the motor by each phase and resultant vibration, but it can also generate relatively large negative sequence currents which result in more heating.

\section{CONCLUSIONS}

1) It is shown that retrofitting a pump load drive with a high-efficiency motor may result in lower energy savings than expected from the efficiency difference shown in the nameplate efficiencies of the old and the new highefficiency motors.

2) The temperature rise of the retrofitted high-efficiency motor may go up if the load system remains unchanged.

3) This paper provides simple equations for the assessments of temperature rise and actual efficiency gain or loss from the retrofitted high-efficiency motor.

4) The fan or pump system may have to be altered in order to gain the full potential of the retrofitted high-efficiency motor.

5) Reliability considerations in terms of temperature rise. downsizing, power factor correction, unbalanced phase voltages, system harmonics, motor mechanical features, and others are discussed.

\section{ACKNOWLEDGMENTS}

The authors would like to thank the Office of Energy Efficiency and Renewable Energy, U.S. Department of Energy for financial support through the Motor Challenge Program. Thanks are due to the Oak Ridge National Laboratory (ORNL) for the support staff and facilities provided for the research work. The authors would also like to express their appreciation to Paul Scheihing, DOE program manager, Mitch Olszewski, ORNL program manager, and Don Adams, group manager, for their support in this research.

\section{REFERENCES}

[1] INDUSTRIAL ELECTRIC MOTOR SYSTEMS, Program Plan, January 1994, U.S. Department of Energy, Office of Industrial Technologies, Office of Energy Efficiency and Renewable Energy

[2] Austin H. Bonnett, "The New NEMA Design E Induction Motor-Characteristics and Performance Compared with Designs A and B," IEEE Industry Applications Society Newsletter, May/June 1994, pp. 8-12.

[3] Motor Master, Version 2.1, Washing State Energy Office, P. O. Box 43165, Olympia, WA 98504-3165.

[4] R. L. Nailen, "Can Field Tests Prove Motor Efficiency?' IEEE Conference Record of Industrial and Commercial Power Systems Technical Conference, 1988 May 2-5, Baltimore, MD, pp.110-116.

[5] NEMA MG-1, National Electrical Manufacturers Association, Washington DC 20037, 1993.

[6] ENERGY MANAGEMENT GUIDE FOR SELECTION AND USE OF POLYPHASE MOTORS. National Electrical Manufacturers Association, Standard Publication N. MG 10-1977. Washington D.C. 20037, 1977.

[7] Pankaj K. Sen, Hector A. Landa, "Derating of Induction Motors Due to Waveform Distortion," IEEE Transactions on Industry Applications, Vol. 26, No. 6 , November/December 1990, pp. 1102-1107.

[8] IEEE RECOMMENDED PRACTICES AND REQUIREMENTS FOR HARMONIC CONTROL IN ELECTRIC POWER SYSTEMS, Project IEEE 519, October 1991.

[9] J. A. Oliver, B. Ben Benerjee, "Power Measurement and Harmonic Analysis of Large Adjustable Speed Drives," IEEE Transactions on Energy Conversion, Vol. 3, No. 2. June 1988, pp. 384-390.

[10] IEEE STANDARD TEST PROCEDURE FOR POLYPHASE INDUCTION MOTORS AND GENERATORS, IEEE Std 112-1991, IEEE Power Engineering Society, New York, N. Y.

[11] Robert E. Oesterlei." Motor Efficiency Test Methods-Apple and Oranges?" Power Transmission Design, 22 (5); pp. 41 43, May 1980.

[12] William D., Biesemeyer, Jeffrey Jowett. "Facts and Fiction of HVAC Motor Measuring for Energy Savings," 
Biesemeyer \#116, Arizona Department of Commerce Energy Office.

\section{APPENDIX 1}

Using symbol $\mathrm{P}$ to represent power, and its suffix for location of power, the effective efficiency of motor with pump-type load is given as follows:

$$
\begin{aligned}
\eta_{\text {eff. }} & =\frac{P_{\text {output of new motor }}-P_{\text {wasted in pump }}}{P_{\text {input of new motor }}} \\
& =\eta_{\text {new }}-\frac{P_{\text {wasted in pump }}}{P_{\text {input of new motor }}}
\end{aligned}
$$

Assuming the additional motor output caused by the excessive speed is wasted and the power absorbed by the load (or pump) changes with the cube of rotating speed, the effective efficiency becomes

$\eta_{\text {eff }}=\eta_{\text {new }}-\frac{\left(\left(\frac{1-S_{\text {new }}}{1-S_{\text {old }}}\right)^{3}-1\right) P_{\text {output of old motor }}}{P_{\text {input of new motor }}}$

where the old and new slips and efficiencies have been defined previously. Substituting

$$
\frac{P_{\text {output of new motor }}}{P_{\text {output of new motor }}}=\left(\frac{1-S_{\text {old }}}{1-S_{\text {new }}}\right)^{3}
$$

into the above effective

efficiency equation gives

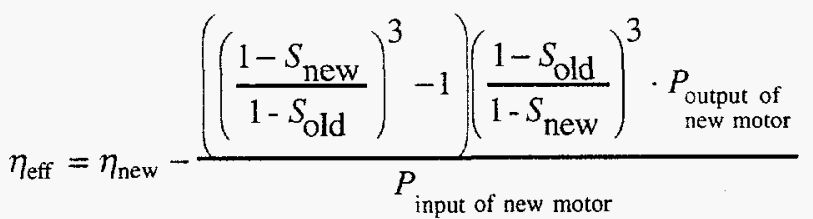

Simplification yields

$\eta_{\text {eff }}=\eta_{\text {new }} \cdot\left(\frac{1-S_{\text {old }}}{1-S_{\text {new }}}\right)^{3}$

Note also that the effective efficiency can be expressed as the product of the old motor efficiency by the ratio of old and new power inputs, i.e.,

$$
\eta_{\text {eff. }}=\eta_{\text {old }} \frac{P_{\text {input of old motor }}}{P_{\text {input of new motor }}}
$$

John S. Hsu (Htsui) (SM' 89 ) was born in China. He received a B.S. degree from Tsing-Hua University, Beijing, China, and a Ph.D. degree from Bristol University, England. He joined the Electrical and Electronics Engineering Department of Bradford University, England, serving there for nearly two years.

After his arrival in the United States, he worked in research and development areas for Emerson Electric Company and later for Westinghouse Electric Corporation. He established the technical innovations for the Westinghouse World Series motors. Many of his design programs are currently used by industry.

Dr. Hsu served as head of the Rotating Machines and Power Electronics Program, Center for Energy Studies, the University of Texas at Austin for over four years. Presently, he is a senior staff scientist of the Digital and Power Electronics Group, Oak Ridge National Laboratory. $\mathrm{He}$ is the author or coauthor of many technical publications and the inventor or co-inventor of seven patents.

Pedro J. Otaduy was born in Euskadi, Spain. He earned the degrees of Industrial Perito and Industrial Engineer in the field of Energy Technologies at the Basque University of Bilbao. He came to the University of Florida with a Fulbright scholarship and earned his MS. and Ph.D. from the Nuclear Engineering Department. He joined the Oak Ridge National Laboratory as an E. P. Wigner Fellow, where he has been part of the research staff for the last fourteen years. He has taught and published in a variety of subjects including nuclear reactor stability, supervisory control, wavelets, and artificial intelligence.

John D. Kueck earned the B. S. degree in physics from Purdue University and the M. S. degree in Electrical Engineering Power Systems from Ohio State University where he was an Ohio Electric Utility Institute Fellow. He is a Registered Professional Engineer and was employed with Sargent and Lundy Engineers, Combustion Engineering and the Carolina Power and Light Company for the first 20 years of his career. He is presently a Development Engineer with the Oak Ridge National Laboratory where he is involved with the Nuclear Plant Aging Research Program and the Motor Challenge Program. Mr. Kueck has authored a number of papers on the subjects of electrical power systems reliability and component degradation.

The submitted manuscript has been authored by Oak Ridge National Laboratory, Oak Ridge, Tennessee 37831-7280, managed by Martin Marietta Energy Systems. Inc. for the U. S. Department of Energy under contract No. DE-AC05-84OR21400. Accordingly, the $\mathrm{U}$. S. Government retains a nonexclusive, royalty-free license to publish or reproduce the published form of this contribution. or allow others to do so. for U. S. Government purposes. 


\section{DISCLAIMER}

This report was prepared as an account of work sponsored by an agency of the United States Government. Neither the United States Government nor any agency thereof, nor any of their employees, makes any warranty, express or implied, or assumes any legal liability or responsibility for the accuracy, completeness, or usefulness of any information, apparatus, product, or process disclosed, or represents that its use would not infringe privately owned rights. Reference herein to any specific commercial product, process, or service by trade name, trademark, manufacturer, or otherwise does not necessarily constitute or imply its endorsement, recommendation, or favoring by the United States Government or any agency thereof. The views and opinions of authors expressed herein do not necessarily state or reflect those of the United States Government or any agency thereof. 